\title{
The relationship between parents' dietary care and food diversity among preschool children in Japan
}

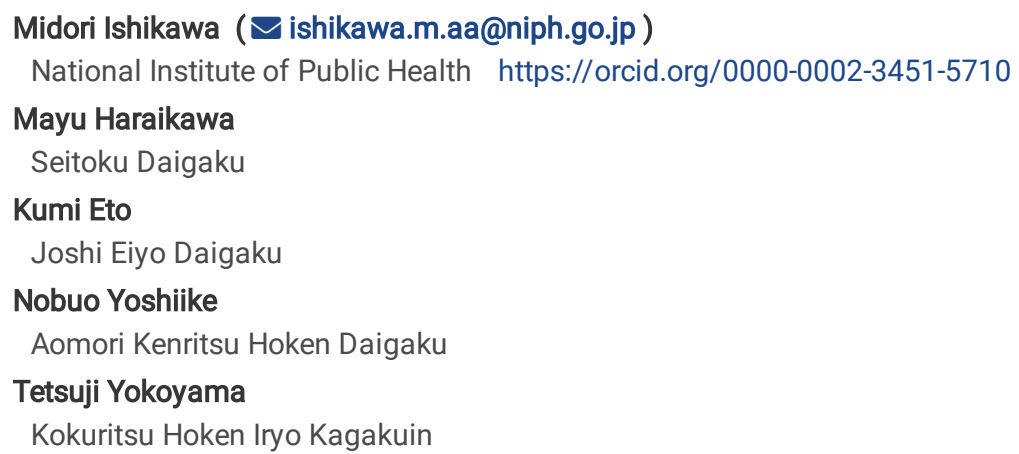

Research

Keywords: preschool children, food diversity, parental care, nutritional balance, snack content, regular mealtimes

Posted Date: March 2nd, 2020

DOI: https://doi.org/10.21203/rs.3.rs-15538/v1

License: (c) (i) This work is licensed under a Creative Commons Attribution 4.0 International License. Read Full License

Version of Record: A version of this preprint was published at Public Health Nutrition on March 5th, 2021. See the published version at https://doi.org/10.1017/S1368980021000963. 


\section{Abstract}

Background Increasing food diversity in early childhood diets is important; however, few studies on parental care emphasize the necessity of ensuring greater food diversity for children. The aim of this study was to identify the relationship between preschool children's dietary diversity and parents' care behaviors related to their diet including contents of foods and snacks, mealtime practice, and parent-child communication.

Methods Data were extracted from the National Nutrition Survey on Preschool Children conducted among households with toddlers and preschoolers in 2015 by Japan's Ministry of Health, Labor and Welfare. Based on 2143 responses from households with children aged 2-6 years, a food diversity score (8 food groups: max of 8 points) was calculated and the distribution was confirmed. The participants were divided into higher ( $\geq 4$ points, $n=1151$ ) and lower ( $\leq 3$ points; $n=992$ ) food diversity groups. A comparison between the two groups examined parents' socioeconomic status, children's health and living conditions, and parental care concerning children's diets ( 13 items, including nutritional balance of foods, snack content, and regularity of mealtimes). Based on the results, a multiple regression analysis was performed relating food diversity scores to the factors of parental socioeconomic status and child health, and a logistic regression analysis was conducted to identify factors of parental care related to the higher food diversity group.

Results Among the higher food diversity group, mothers were older, subjective economic status was higher, parents' skipped breakfast skipping less, and children had fewer caries and engaged in less than two hours of screen time per day. Parental care concerning children's diets was the factor most strongly associated with children's food diversity scores. Among such habits, those factors most strongly associated with higher food diversity were nutritional balance of foods (OR: 1.76; $95 \%$ Cl: $1.44-2.16 ; \mathrm{p}<.0001$ ), snack contents (OR: $1.41 ; \mathrm{Cl}: 1.07-1.86 ; \mathrm{p}=0.014$ ), and regular mealtimes (OR: 1.30; Cl: 1.08-1.55; $p=0.005)$.

Conclusion The findings indicate the importance of parents paying attention to the contents of children's foods and snacks, ensuring that children eat regularly, and increasing the diversity of their diets.

\section{Background}

The eating habits developed in early childhood affect long-term nutritional status and growth $[1,2]$. Eating a variety of foods is particularly well recognized as being important for optimal nutritional status across the life course [3]. According to the United Nations Food and Agriculture Organization (FAO), food variety refers to the consumption of a mixture of foods from a range of food groups. Accordingly, global dietary guidelines recommend that people eat a wide variety of foods as part of a nutritious diet. The FAO promotes the assessment of household and individual dietary diversity worldwide [4, 5], and the organization introduced a food diversity score (FDS) whereby diversity in the number of food groups can be used as an indicator to assess the nutritional quality of the whole diet [4]. The FDS will enable to assess the diet of people at local level.

Recognizing the importance of developing dietary diversity during early childhood, More and Emmett proposed a dietary plan with practical food amount based on a variety of foods to ensure intake adequate nutrient intakes within preschool children's energy requirements [6, 7]. However, many young children develop unbalanced diets due to picky eating, which often persist through later childhood and into adulthood [8, 9]. The National Nutrition Survey on Preschool Children conducted in Japan reported that approximately $80 \%$ of parents expressed frequent concerns about the dietary habits of their children [10]. Studies have particularly linked limited dietary variety to low intakes of fruits and vegetables and high intakes of unhealthy processed food [11, 12], with possible consequences including higher body mass index and obesity [12].

Preschool children's dietary behaviors and physical activity are associated with home environment and parental behaviors [13]. Many parents recognize the need to be aware of and closely manage their children's diet to ensure food diversity, including contents of foods and snacks (e.g., nutritional balance, flavoring and seasoning, and amount of food), mealtime practice (e.g., regular mealtimes and chewing well), and parent-child communication (e.g., cooking meals with children and eating together) [10]. In addition, parental behaviors may be efficient in improving children's diet quality [14]. Research has indicated that parents and children cooking meals together is related to higher food diversity of children's diets [15]. However, few academic studies have comprehensively examined what parental care behaviors are related to children's food diversity. Therefore, the aim of this study was to identify the relationship between preschool children's food diversity and their parents' care behaviors with regard to their diet including contents of foods and snacks, mealtime practice, and parent-child communication.

\section{Methods}

Data for this study were retrieved from the National Nutrition Survey on Preschool Children (NNSPC), which was conducted in September 2015 by the Ministry of Health, Labor, and Welfare of Japan (MHLW) [10].

\section{Study population and procedure}

Figure 1 shows the study population and procedure. Children aged $\leq 6$ years as of May 31, 2015 were randomly selected from households among 1,106 districts for the Comprehensive Survey of Living Conditions, conducted by the MHLW. Three districts affected by heavy rain in September 2015 were excluded from the survey sampling. First, the MHLW explained the survey method to the prefectures. Subsequently, the prefectural public 
health center employed investigators to visit the households selected for this survey. The investigators asked the children's mothers (or the caregiver involved in providing food to the child) to complete a questionnaire, which was collected at a later date. In total, 2,992 households with 3,936 children aged $\leq 6$ years participated in the survey. The response rate of the survey was $56.8 \%$. The questionnaires associated with 65 children were excluded because information on age was not available. Finally, 3,871 questionnaires were collected for analysis [10]. A database was prepared by the Maternal and Child Health Division, Department of Equal Employment and Children's Family, MHLW.

The National Nutrition Survey on Preschool Children has two types of questionnaires, one of which is restricted to infants aged $<2$ years and the other of which encompasses children aged 2-6 years. Data obtained from the latter questionnaire were used in this study. In total, 2143 persons responded to all items consistent with the purpose of this study.

\section{Measurement}

Children's dietary patterns in relation to the eight food groups (grains, fish, meat, eggs, soybeans/soy products, vegetables, fruit, and milk) were evaluated as objective variables, as well as their intake of processed foods, whereby four items (sweetened beverages, confectioneries, instant noodles, and fast food) were investigated. The survey inquired how often the children consumed foods in each group ( $\geq 2$ times per day, once a day, 4-6 days per week, 1-3 days per week, or less than once a week or rarely) $[10,16]$. The FAO's food diversity score (FDS) was applied to assess the nutritional quality of the whole diet [5].

Thirteen items assessed parents' care behavior in relation to children's diets. We posed the question "Are you (parent) careful about your child's diet?" with regard to the following 13 items: 1) food (seven items encompassing nutritional balance, flavoring and seasoning, size or softness, assorted arrangements and colors, amount) and snack (contents, amount); 2) mealtime practice (three items comprising regular mealtimes, chewing well, table manners); and 3) "parent-child communication (three items encompassing enjoyment of eating, eating together, cooking together). Each item was scored based on "yes" or "no" responses.

Explanatory variables related to parents included their relationships with their children, age of mother, current employment status of mother, household structure (i.e., presence of other children, grandparents, and others), subjective economic status, leisure time (i.e., affluent, somewhat, neither, not so much, cannot afford at all), the place where the child spends time during the day (i.e., nursery school, kindergarten, centers for early childhood education and care, grandparents and relatives, or none of the above) and lifestyle regarding eating breakfast with parents. Moreover, data concerning children's age; height; weight; nutritional status (degree of obesity); food allergies; tooth decay; and time spent on TV, video, and games were obtained.

\section{Nutritional status of children}

The nutritional status of children was determined based on body weight and height. The degree of obesity (\%) was calculated using the following formula: self-reported body weight (g) - standard body weight (g) for height/standard body weight (g) for height $\times 100$. The judgment criteria for the degree of obesity were "obese" ( $\geq 30 \%)$, "overweight" (20\%-30\%), "tendency to be overweight" (15\%-20\%), "standard" (-15\% to +15\%), "tendency to be underweight" (less than 15\% to less than 20\%), and "underweight" (less than $20 \%$ ). The standard body weight was calculated using the formula of standard body weight for height in Japanese children $[17,18]$. The formula does not consider age because the standard body weight for height curves were almost identical for children aged 1-6 years [19].

\section{Statistical analysis}

The FDS of children comprised the total number of eight food groups (grains, fish, meat, eggs, soybeans/soy products, vegetables, fruits, and milk) being consumed at least once a day $[4,10,19]$. The FDS was one point if consumption occurred once or more per day or zero points if less than that. There were eight types of foods; thus, the maximum score was eight points. Once the FDS distribution was identified, the FDS was divided into two groups according to medians: 1) three or fewer points and 2) four or more points [4]. The processed food score was calculated according to the total number of four food items (sweetened beverages, confectioneries, instant noodles, and fast food) being consumed at least once a day [4]. As in the case of FDS, the processed food score was calculated as a score of one point if the food type was consumed at least once a day or zero points if less than that. There were four types of foods; thus, the maximum score was four points.

The sex of the parent who answered the questionnaire, age, and socioeconomic status as well as children's sex; nutritional status; food allergies; tooth decay; and time spent on TV, video, and games were compared between the two FDS groups. Initially, parents' socioeconomic status was compared between children's FDS groups, and then, children's health and lifestyle were analyzed by the two FDS groups. Furthermore, the total value calculated from the 13 items of the parent's care behavior in children's diets was compared between the two FDS groups.

Multiple regression analysis analyzed relationships between FDS scores and several variables, including the total value of the parent's care behaviors in children's diets; subjective socioeconomic status; food allergies; tooth decay; and time spent on TV, video, and games, as well as the

Page 3/19 
child's age and mother's age. The continuous variables included the total value of the parent's care behaviors in children's diets, the child's age, and the mother's age. The nominal variables such as subjective socioeconomic status; food allergies; tooth decay; and time spent on TV, video, and games were converted to an ordinal scale.

Next, we used logistic regression to specifically analyze the relationship between the variables and the higher FDS group. Multivariate analysis was performed for each of the 13 items measuring parental care in relation to children's diets using a logistic regression model that adjusted for the parent's (i.e., mother or father) relationship with the child, child's sex (i.e., male or female), employment status of the mother (i.e., yes or no), and household structure (i.e., presence of other children, grandparents, and others) (Model 1).

Additional multivariate analysis was performed for each of the 13 items measuring parental care in relation to children's diets using a logistic regression model that adjusted for the parent's (mother or father) relationship with the child, child's sex, employment status of the mother (i.e., yes or no), household structure (i.e., presence of other children, grandparents, and others), subjective economic status (i.e., affluent, somewhat, neither, not so much, or not able to afford at all), leisure time (i.e., affluent, somewhat, neither, not so much, or not able to afford at all), and place where the child spends time during the day (i.e., nursery school, kindergarten, center for early childhood education and care, with grandparents, with relatives, staying at home) (Model 2).

All statistical analyses were performed using SAS software, version 9.2 (SAS Institute, Inc., Cary, NC, USA). A probability $(p)$ value of $<0.05$ was considered statistically significant.

\section{Results}

Figure 2 shows the children's FDS distribution. Scores ranged from 0 to 8 points, and there was a normal distribution with a median of 4 points. The median was divided into two groups: $\geq 4$ points $(n=1151)$ and $\leq 3$ points $(n=992)$.

Table 1 compares the characteristics of mother's age $(p=0.001)$ and employment status, family members living together, subjective economic status and leisure time, and the places where children spend the day according to FDS group. The "higher" FDS group was associated with higher maternal age and subjective economic status ( $<$ 0.0001) than the "lower" FDS group. In addition, children of the higher FDS group were more likely to be in nursery school $(p=0.041)$, whereas children of the lower FDS group were more commonly in kindergarten ( $p=0.034)$. A higher proportion of parents in the lower FDS group tended to skip breakfast $(p=0.0002)$. There were no significant differences in the other variables between the two groups.

Table 2 compares the children's age; sex; nutritional status; food allergies; tooth decay; and time spent on TV, video, or games between the two FDS groups. Overall obesity rates among the children were low. The children in the lower FDS group had more tooth decay $(p=0.006)$, whereas those in the higher FDS group had spent less than two hours per day on TV, video, or games during the weekdays $(p=0.005)$ and weekends $(p=0.002)$.

Table 3 presents differences in food intake between two FDS groups. The higher FDS group had higher frequencies of grains, fish, meat, eggs, soybeans/soy products, vegetables, fruits, and milk intake than the lower FDS group but less frequencies of instant noodle and fast-food intake.

Table 4 compares values for parental care in relation to children's diets (13 items) between the two FDS groups. With regard to "food," the nutritional balance $(p<0.001)$, flavoring and seasoning $(p=0.004)$, and assorted arrange and colors $(p=0.002)$ of the higher FDS group were significantly higher than those of the lower FDS group. With regard to "snack," contents $(p<0.001)$, and amount $(p=0.015)$ of the higher FDS group were significantly higher than those of lower FDS group. The higher FDS group also received significantly higher values for factors under "mealtime practice," specifically, regular mealtimes ( $p<0.001)$ and chewing well $(p=0.002)$. Lastly, in "parent-child communication," the higher FDS group had significantly higher scores for enjoying eating $(p=0.032)$ and eating together $(p=0.030)$ than the lower FDS group.

Table 5 shows the results of the multiple regression analysis of factors related to FDS. Parental care behaviors concerning children's diets was the factor most strongly associated with children's food diversity scores. The total number of the items of parental care of children's diets ( $p<0.001)$ and mother's age $(p=0.01)$ were positively associated with FDS, whereas subjective economic status $(p=0.003)$ and TV, video, or games during the weekdays $(p=0.01)$ were negatively associated with FDS.

Table 6 shows the results of the associations between "parental care of children's diets" and "FDS group" using step-wise multivariate analysis.

A number of Model 1 variables were identified as predictors for FDS. Five of seven factors in the food category were positively and significantly associated with FDS: nutritional balance (odds ratio $[\mathrm{OR}]=1.91 ; 95 \%$ confidence interval $[\mathrm{Cl}]=1.56-2.35 ; \mathrm{p}<0.001)$; flavoring and seasoning $(\mathrm{OR}=$ $1.24 ; 95 \% \mathrm{Cl}=1.03-1.48 ; \mathrm{p}=0.022)$; assorted arrange and colors $(\mathrm{OR}=1.35 ; 95 \% \mathrm{Cl}=1.08-1.69 ; \mathrm{p}=0.009)$. In the snack category were positively and significantly associated with FDS; contents $(\mathrm{OR}=1.72 ; 95 \% \mathrm{Cl}=1.32-2.25 ; \mathrm{p}<0.001)$; and amount $(\mathrm{OR}=1.23 ; 95 \% \mathrm{Cl}=1.03-1.48 ; \mathrm{p}=0.026)$. Two of the three factors in the "mealtime practice" category were positively associated with FDS, namely, regular mealtimes $(\mathrm{OR}=1.45 ; 95 \% \mathrm{Cl}=$ 
$1.21-1.73 ; \mathrm{p}<.0 .001)$ and chewing well $(\mathrm{OR}=1.34 ; 95 \% \mathrm{Cl}=1.10-1.63 ; \mathrm{p}=0.003)$. In regard to the parent-child communication, only eating together $(\mathrm{OR}=1.23 ; 95 \% \mathrm{Cl}=1.02-1.48 ; \mathrm{p}=0.034)$ was significantly associated with FDS.

The Model 2 analysis confirmed the variables associated with FDS. For "food," the same results as those identified for Model 1 above were achieved for nutritional balance $(\mathrm{OR}=1.91 ; 95 \% \mathrm{Cl}=1.56-2.35 ; \mathrm{p}<.0001)$ and flavoring and seasoning $(\mathrm{OR}=1.24 ; 95 \% \mathrm{Cl}=1.03-1.48 ; \mathrm{p}=0.020)$.; $\mathrm{However}$, slightly different yet still significant results were found related to assorted arrange and colors $(\mathrm{OR}=1.34 ; 95 \% \mathrm{Cl}=1.07-1.68 ; \mathrm{p}=0.011)$. Further, for "snack," were associated with FDS, contents $(\mathrm{OR}=1.72 ; 95 \% \mathrm{Cl}=1.31-2.24 ; \mathrm{p}<0.001)$ and amount $(\mathrm{OR}=1.23 ; 95 \% \mathrm{Cl}=1.03-1.48 ; \mathrm{p}=0.027)$.

Similarly, for the "mealtime practice" category, the same results were identified for chewing well $(\mathrm{OR}=1.34 ; 95 \% \mathrm{Cl}=1.10-1.63 ; \mathrm{p}=0.004)$; however, slightly different values were found regarding the association between FDS and regular mealtimes $(\mathrm{OR}=1.44 ; 95 \% \mathrm{Cl}=1.21-1.72 ; \mathrm{p}<.0 .001)$. In the parent-child communication category, eating together $(\mathrm{OR}=1.22 ; 95 \% \mathrm{Cl}=1.01-1.48 ; \mathrm{p}=0.037)$ was again the only factor significantly associated with FDS.

The results of the stepwise analysis identified several predictors for FDS, including nutritional balance of food $(\mathrm{OR}=1.76 ; 95 \% \mathrm{Cl}=1.44-2.16 ; p<$ $0.001)$, snack contents $(\mathrm{OR}=1.41 ; 95 \% \mathrm{Cl}=1.07-1.86 ; p=0.0014)$, and regular mealtimes $(\mathrm{OR}=1.30 ; 95 \% \mathrm{Cl}=1.08-1.55 ; p=0.005)$.

\section{Discussion}

This study identified a relationship between preschoolers' dietary diversity and parental care of the contents of children's foods and snacks, as well as regular mealtimes. In other words, FDS could be used to assess children's diet quality.

Greater food diversity was associated with higher maternal age and subjective economic status, as well as younger child age (nursery school vs. kindergarten), as well as higher frequencies of grains, fish, meat, eggs, soybeans/soy products, vegetables, fruits, and milk intake. Lower food diversity was associated with a higher likelihood that parents skipped breakfast and greater consumption of processed or fast foods, as well as more time spent per day on TV, video, or games. Finally, being in the higher FDS group was significantly associated with greater parental care about the contents of children's diets and qualitative aspects of eating, such as regular mealtimes and eating together.

In Japan, where the social trend of people owning and spending time on smart phones or tablet PC has been increasing, it was reported that a mother's unhealthy lifestyle correlates strongly with prolonged screen time among school-aged children [20]. A European longitudinal study targeted 2-9 year old children and indicated the effects of TV viewing and other screen activities for young children, both on their consumption of sugary drinks and an increase in BMI [21]. In Japan as well, it would be necessary to study the effect of screen time during early childhood on the children's food and snack intake.

In Japan's NNSPC, the proportion of parental participants who ensured the nutritional balance of foods (72.0\%) was higher than those who were careful about snack contents (12.4\%) and having regular mealtimes (45.0\%). The results indicate that parents who reported diverse diets are more likely to ensure regular mealtimes. The effects of meal timing and frequency on children's health has been a research topic for many years, and preparing foods and snacks and having children eat them at regular times has been identified as an important daily habit. Considering how to change the behavior of parents and children who do not have regular mealtimes is a complex issue. Previous study findings have indicated a close relationship between children's mealtimes and their parents' working times and other lifestyle elements [22]; in this context, behavior change can be difficult. Moreover, many young children also receive foods at places outside the home, such as at nursery schools and kindergartens. In this context, our findings of less dietary diversity among kindergartners are notable.

Much of the literature emphasizes the importance for young children to eat a variety of foods to ensure appropriate nutrient intake [6]. Metcalfe et al. found that family food involvement at age three is predictive of healthier dietary intake at age four (increased consumption of fruits and vegetables, decreased consumption of fast food) [23]. It may be possible to change parents' behavior and increase dietary diversity by providing nutritional guidance on the contents of foods and snacks consumed both in and outside out of the home [24]. In addition, to combat picky eating habits, it is important to promote interventions that support skills for food choice and preparation [25] and food environments that change the diet quality at home [26, 27]. Ishikawa et al. identified a significant relationship between parents and children cooking together and dietary diversity [15]; however, this finding rather emphasizes the importance of eating meals together, and parent-child cooking activities were not directly associated with diversity in children's diets. According to Helland et al, behaviors that can improve food diversity in early childhood include to modeling, responsive feeding, repeated exposure, and enjoyable meals [11].

A study conducted by Fernandez et al. indicated that higher food diversity may be positively associated with increasing BMI of children [12]; however, in our study, no significant association was found between food diversity and this element of child nutritional status. This may be due to lower overall obesity rates among the study's participants.

According to the results of this study, in order to broaden the food diversity of children, it is important to consider the content of snacks as well as foods. Prior research has identified fruits, milk, and dairy products among the top 10 most frequently eaten foods and beverages consumed as snacks by children in Australia, China, Mexico, and the US; however, confectionery, cookies, candy, ice creams, and cakes are also seen among the top 10 snacks. These undermine the nutritional benefits of healthier foods and contribute to poor dental health [28]. 
According to the results of the NNSPC, $41.9 \%$ of 2-3-year-old and $28.9 \%$ of 5-years-and-older children consume sweetened beverages and confectionaries twice a day or more as snacks. The proportion of those who did not have a fixed snack time was $43.7 \%$ [10]. It is important to include snack contents and timing in early childhood nutritional education. However, few reports have focused on the effects of snack contents, amount, and timing on the health of preschool children in Japan, although some dental investigations of preschool children suggest a significant relationship between snack items (e.g., sweet buns) and caries [29, 30, 31].

Despite a broad agreement that snacks contribute significant energy to children's diets, evidence of the effects of snacks on health status, especially in children, is still weak. The lack of consistent evidence related to this issue may be partly due to a non-standardized definition of snack contents [32]. In the future, it will be necessary to research the actual situation of snack contents and amount to decide on snacks for young children.

The systematic review study presents negative food parenting practices, such as setting restrictions and pressurizing to eat, compared with the positive practices such as being a role model, setting healthy limits, or providing encouragement. Therefore, it would be beneficial for future studies to include positive parenting behaviors for identifying how these can be supported and translated into public health interventions [33]. The active guidance/education will be important to make the parental behaviors on child's food consumption desirable [34].

There were several limitations to this study that should be addressed. First, the response rate of the survey was only $56.8 \%$. We relied on the 2015 database of the National Nutrition Survey on Preschool Children conducted by the MHLW. In that investigation, 3,871 questionnaires were collected from 3,936 children; however, only 2,143 participants responded to all of the survey items. The most unanswered items concerned height, weight, and subjective economic status. Although height and weight are measurable, it might have been difficult for some parents to subjectively gauge their economic status. Since this survey is conducted every 10 years by the MHLW, it is necessary to devise a method to increase the response rate for such items in future surveys.

Items related to the dietary habits of parents were limited. In many cases, parental behaviors related to their children's diets may be influenced by limitations in their own dietary habits.

In addition, it is unknown how the participants' care of children's diets may have impacted children's physical and mental development. A number of studies have examined associations between mealtimes and the physical and mental health of children [22, 31, 35], and a few researchers have reported a relationship between mealtimes and food diversity $[13,23]$. Therefore, further research on this issue is required.

Lastly, information regarding food and snack contents and behaviors was self-reported, as was information concerning TV habits and socioeconomic status. In the future, it will be necessary to research the actual situation of lifestyles and parents' food and snack behaviors rather than rely on self-reported information.

\section{Conclusion}

This study assessed relationships between young children's dietary diversity and parental care behaviors regarding foods and found that parental care was a predictor of greater food diversity. The food diversity of children's diets is strongly based on parents' care concerning the contents of children's foods and snacks and regular mealtimes. The results of this study can be used to inform efforts to develop and implement nutritional guidance education for parents and nutrition staff, including school meal providers.

\section{Abbreviations}

MHLW: Ministry of Health, Labour and Welfare; $\mathrm{MCH}$ : maternal and child health; SD: Standard deviation; OR: Odds ratio; Cl: Confidence interval; Lsmeans: Least squares mean; SE: Standard Error

\section{Declarations}

\section{Ethics approval and consent to participate}

The study protocol was approved by the Ethics Committee of the National Institute of Public Health, Wako, Saitama, Japan (NIPH-TRN\#12021, February 1, 2018).

\section{Consent for publication}

Not applicable. 
Permission for the use of the dataset in the current study was obtained from the MHLW, Japan. All data belong to the MHLW, and the database cannot be used for other studies.

\section{Competing Interests}

The authors declare that they have no competing interests.

\section{Funding}

This study was funded by a Health and Labour Sciences Research Grant in 2018 for the "Development of a food, nutrition, and dietary guide for healthy development in early childhood" (H29 Sukoyaka ippan 003 to MI). The funders had no role in study design, data collection/analysis, decision to publish, or preparation of the manuscript.

\section{Authors' contributions}

MI designed the research and wrote the manuscript and TY provided statistical analysis support. KE, MH, TY, NY contributed to interpreting the data and revising the manuscript for scientific clarity. All authors read and approved the final manuscript.

\section{Acknowledgments}

No applicable.

\section{References}

1. Meeting the challenge of a new era for achieving healthy diet and nutrition. Outcomes of the 2nd Global Nutrition Policy Review. 2018. http://www.who.int/nutrition/events/2016_side-event-outcome-2nd-globalnutritionpolicyreview-2dec/en/. Accessed 3 November 2019.

2. Nishida C. Preliminary results of the $2^{\text {nd }}$ Global nutrition policy review: A global perspective. Meeting the challenge of a new era for achieving healthy diet and nutrition. Outcomes of the 2nd Global Nutrition Policy Review. 2018. http://www.who.int/nutrition/events/2016_side-eventpresentation-Nishida-preliminaryresults-2ndGNPR.pdf?ua=1. Accessed 3 November 2019.

3. Herman DR, Baer MT, Adams E, Cunninham-Sabo L, Duran N, Johnson DB, et al. Life course perspective: Evidence for the role of nutrition. Matern Child Health J. 2014;18:450-61.

4. Food and Agriculture Organization (FAO). Guidelines for measuring household and individual dietary diversity. http://www.fao.org/3/ai1983e.pdf (2013).

5. Dietary Assessment: A resource guide to method selection and application in low resource settings. http://www.fao.org/3/i9940en/l9940EN.pdf (2018).

6. More JA, Emmett PM. Evidenced-based, practical food portion sizes for preschool children and how they fit into a well-balanced, nutritionally adequate diet. J Hum Nutr Diet. 2015;28(2):135-54; doi:10.1111/jhn.12228.

7. Richter LM, Daelmans B, Lombardi J, Heymann J, Boo FL, Behrman JR, et al. Investing in the foundation of sustainable development: pathway to scale up for early childhood development. Lancet. 2017;389(10064):103-18

8. Black MM, Walker SP, Fernald LCH, Andersen CT, DiGirolamo AM, Lu C, et al. Early childhood development coming of age: through the life course. Lancet. 2017;389(10064):77-90

9. Sandvik P, Ek A, Eli K, Somaraki M, Bottai M, Nowicka Picky eating in an obesity intervention for preschool-aged children - what role does it play, and does the measurement instrument matter? Int J Behav Nutr Phys Act. 2019;16:76; doi:https://doi.org/10.1186/s12966-019-0845-y.

10. Ministry of Health, Labour and Welfare (MHLW). Report on National nutrition survey on preschool children. https://www.mhlw.go.jp/stf/seisakunitsuite/bunya/0000134208.html (2016). Accessed 3 November 2019.

11. Helland SH, Bere E, Øverby NC. Study protocol for a multi-component kindergarten-based intervention to promote healthy diets in toddlers: a cluster randomized trial. BMC Public Health. 2016;16:273; doi:10.1186/s12889-016-2952-x.

12. Fernandez C, Kasper NM, Miller AL, Lumeng JC, Peterson KE. Association of dietary variety and diversity with body mass index in US preschool children. Pediatrics. 2016;137(3): e20152307; doi:https://doi.org/10.1542/peds.2015-2307. 
13. Spurrier NJ, Magarey AA, Golley R, Curnow F, Sawyer Relationships between the home environment and physical activity and dietary patterns of preschool children: a cross-sectional study. Int J Behav Nutr Phys Act. 2008;5:31; doi:https://doi.org/10.1186/1479-5868-5-31.

14. Romanos-Nanclares A, Zazpe I, Santiago S, Marín L, Rico-Campà A, Martín-Calvo N. Influence of parental healthy-eating attitudes and nutritional knowledge on nutritional adequacy and diet quality among preschoolers: The SENDO Project. Nutrients. 2018;10:1875.

15. Ishikawa M, Eto K, Miyoshi M, Yokoyama T, Haraikawa M, Yoshiike N. Parent-child cooking meal together may relate to parental concerns about the diets of their toddlers and preschoolers: a cross-sectional analysis in Japan. Nutr. J. doi: 1186/s12937-019-0480-0 .

16. Kamata Y, Kurasawa N, Tohmata Y, Tanno K, Ono M, Kobayashi K, et al. Validity of food intake frequency questionnaire "National survey of preschool children" for food group intake: A cross-sectional study at nursery schools in Sendai City. Kousei no Shihyo (Indicator of Welfare). 2018;65(8):29-34. (in Japanese) https://www.hws-kyokai.or.jp/paper/120-2016-02-15-03-07-32/2208-201808-5.html Accessed 15 November 2019. (in Japanese)

17. The Japanese Society for Pediatric Endocrinology. Assessment of physical status for Japanese infants and children. http://jspe.umin.jp/jspe_test/medical/taikaku.html. Accessed 15 November 2019. (in Japanese)

18. Kato N, Takimoto H, Yokoyama T. Technical report for Japanese National Growth Survey for infants and children in 2010. In: Report of a study on statistical analyses, methods, and utilization of Japanese National Growth Survey for infants and children. 2012, p.111-43. https://www.niph.go.jp/soshiki/07shougai/hatsuiku/houkoku120617.pdf. Accessed 3 November 2019.

19. Ministry of Health, Labour and Welfare (MHLW). Study team on statistical analysis of assessment of physical growth in Japanese children. A manual for the assessment of physical growth in Japanese children. Tokyo: MHLW; 2012. p.48. (in Japanese)

20. Yamada M, Sekine M, Tatsuse T. Parental Internet Use and Lifestyle Factors as Correlates of Prolonged Screen Time of Children in Japan: Results From the Super Shokuiku School Project, J Epidemiol. 2018;28(10):407-

21. Olafsdottir S, Berg C, Eiben G, Lanfer A, Reisch L, Ahrens W, Kourides Y, Molna'r D, Moreno LA, Siani A, Veidebaum T, Lissner L on behalf of the IDEFICS consortium. Young children's screen activities, sweet drink consumption and anthropometry: results from a prospective European study. Euro J Clin Nutr. 2014;68:223-28.

22. Bekelman TA, Bellows LL, Clark L, Thompson DA, Kemper G, McCloskey ML, et al. An ecocultural perspective on eating-related routines among low-income families with preschool-aged children. Qual Health Res. 2019;29(9):1345-57; doi:10.1177/1049732318814540.

23. Metcalfe JJ, Fiese BH, STRONG Kids 1 Research Team. Family food involvement is related to healthier dietary intake in preschool-aged children. 2018;1(126):195-200; doi:10.1016/j.appet.2018.03.021.

24. Moreira T, Severo M, Oliveira A, Ramos E, Rodrigues S, Lopes C. Eating out of home and dietary adequacy in preschool children. Br J Nutr. 2015;114(2):297-305; doi:10.1017/S0007114515001713.

25. Muehlhoff E, Wijesinha-Bettoni R, Westaway E, Jeremias T, Nordin S, Garz Linking agriculture and nutrition education to improve infant and young child feeding: Lessons for future programmes. Matern Child Nutr. 2017;13(S2):e12411; doi:https://doi.org/10.1111/mcn.12411.

26. Robson SM., Ziegler ML, McCullough MB, Stough CO, Zion C, Simon SL, et al. Changes in diet quality and home food environment in preschool children following weight management. Int J Behav Nutr Phys Act. 2019;16(16); doi:https://doi.org/10.1186/s12966-019-0777-6.

27. Ishikawa M, Eto K, Haraikawa M, Sasaki K, Yamagata Z, Yokoyama T, et al. Multi-professional meetings on health checks and communication in providing nutritional guidance for infants and toddlers in Japan: a cross-sectional, national survey-based study. BMC Pediatr. 2018;18:325; doi:https://doi.org/10.1186/s12887-018-1292-7.

28. Wang D, van der Horst K, Jacquier EF, Afeiche MC, Eldridge AL. Snacking patterns in children: A comparison between Australia, China, Mexico, and the US. Nutrients. 2018;10:198; doi:10.3390/nu10020198.

29. Goto M, Yamamoto Y, Saito R, Fujino Y, Ueno S, Kusuhara K. The effect of environmental factors in childcare facilities and individual lifestyle on obesity among Japanese preschool children: a multivariate multilevel analysis. Medicine (Baltimore). 2019;98(41):e17490; doi:10.1097/MD.0000000000017490.

30. Mukouyama C, Koike Y, Hirohara T. Transitional changes in the prevalence of dental caries in children and preventive strategies: A review of nationwide annual surveys in Japan. Oral Hlth Prev Dent. 2018;16(2):107-11; doi:10.3290/j.ohpd.a40325.

31. Watanabe M, Wang DH, ljichi A, Shirai C, Zou Y, Kubo M, et al. The influence of lifestyle on the incidence of dental caries among 3-year-old Japanese children. Int J Environ Res Public Health. 2014;11(12):12611-22.

32. Younginer NA, Blake CE, Davison KK, Blaine RE, Ganter C, Orloski A, et al. "What do you think of when I say the word 'snack'?" towards a cohesive definition among low-income caregivers of preschool-age children. Appetite. 2016;98:35-40; doi:10.1016/j.appet. 2015.12.002.

33. Blaine R, Alexandria K, Davison KK, Klabunde R, Fisher JO. Food parenting and child snacking: a systematic review. Int J Behav Nutr Phys Act. 2017;14:146.

34. Yee AZ., Lwin MO, Ho SS. The influence of parental practices on child promotive and preventive food consumption behaviors: a systematic review and meta-analysis. Int J Behav Nutr Phys Act. 2017;14:47.

35. Fukuda K, Hasegawa T, Kawahashi I, Imada S. Preschool children's eating and sleeping habits: late rising and brunch on weekends is related to several physical and mental symptoms. Sleep Med. 2019;61:73-81; doi: 10.1016/j.sleep.2019.03.023. 


\section{Tables}

Table区 Parents' socio-economic status by food diversity group 


\begin{tabular}{|c|c|c|c|c|c|c|c|}
\hline & & & \multicolumn{5}{|c|}{ Food diversity score group } \\
\hline & & & \multicolumn{2}{|c|}{$\begin{array}{l}\text { Higher ( } \geq 4 \\
\text { points) }\end{array}$} & \multicolumn{3}{|c|}{$\begin{array}{l}\text { Lower }(\leq 3 \\
\text { points) }\end{array}$} \\
\hline & & & \multicolumn{2}{|c|}{$\begin{array}{l}(n=1151 \\
53.7 \%)\end{array}$} & \multicolumn{2}{|c|}{$\begin{array}{l}(n=992 \\
46.3 \%)\end{array}$} & \multirow[b]{2}{*}{ प } \\
\hline & & & $\mathrm{n}$ & $\%$ & $\mathrm{n}$ & $\%$ & \\
\hline \multirow{3}{*}{\multicolumn{2}{|c|}{ Relationship with their child }} & mother & 1130 & 98.2 & 968 & 97.6 & 0.338 \\
\hline & & father & 21 & 1.8 & 24 & 2.4 & \\
\hline & & & mean & SD & mean & SD & $\mathrm{p}$ \\
\hline Age of mother (years old)† & & mean, SD & 36.3 & 5.0 & 35.5 & 5.3 & 0.001 \\
\hline \multirow[t]{3}{*}{ Employment status of mother } & \multirow[t]{3}{*}{ Currently work } & yes & 654 & 56.8 & 558 & 56.3 & 0.791 \\
\hline & & no & 497 & 43.2 & 434 & 43.8 & \\
\hline & & & $\mathrm{n}$ & $\%$ & $\mathrm{n}$ & $\%$ & प \\
\hline \multirow[t]{6}{*}{$\begin{array}{l}\text { Household structure (whether } \\
\text { living together or not) }\end{array}$} & Single & $\begin{array}{l}\text { mother or father and one } \\
\text { child }\end{array}$ & 40 & 3.5 & 46 & 4.6 & 0.439 \\
\hline & & $\begin{array}{l}\text { mother or father and } \\
\text { grandparent and one child }\end{array}$ & 40 & 3.5 & 25 & 2.5 & \\
\hline & Two generations & $\begin{array}{l}\text { mother and father and one } \\
\text { child }\end{array}$ & 192 & 16.7 & 150 & 15.1 & \\
\hline & & $\begin{array}{l}\text { mother and father and } \\
\text { children }\end{array}$ & 684 & 59.4 & 599 & 60.4 & \\
\hline & Three generations & $\begin{array}{l}\text { mother and father and } \\
\text { grandparent and children }\end{array}$ & 194 & 16.9 & 170 & 17.1 & \\
\hline & others & $\begin{array}{l}\text { others (living together with } \\
\text { non-family adults) }\end{array}$ & 1 & 0.1 & 2 & 0.2 & \\
\hline \multirow{6}{*}{$\begin{array}{l}\text { Subjective economic } \\
\text { status }\end{array}$} & & affluent & 98 & 8.51 & 79 & 8.0 & $<.0001$ \\
\hline & & somewhat & 282 & 24.5 & 166 & 16.7 & \\
\hline & & neither & 379 & 32.9 & 328 & 33.1 & \\
\hline & & not so much & 299 & 26.0 & 325 & 32.8 & \\
\hline & & no afford not at all & 93 & 8.1 & 93 & 9.4 & \\
\hline & & do not want answer & 0 & 0.0 & 1 & 1.0 & \\
\hline \multirow[t]{6}{*}{ Leisure time } & & affluent & 93 & 8.1 & 81 & 8.2 & 0.398 \\
\hline & & somewhat & 274 & 23.8 & 216 & 21.8 & \\
\hline & & neither & 244 & 21.2 & 233 & 23.5 & \\
\hline & & not so much & 416 & 36.1 & 371 & 37.4 & \\
\hline & & no afford not at all & 124 & 10.8 & 90 & 9.1 & \\
\hline & & do not want answer & 0 & 0.0 & 1 & 0.1 & \\
\hline \multirow{8}{*}{$\begin{array}{l}\text { Place where the child spends } \\
\text { time during the day }\end{array}$} & \multirow[t]{2}{*}{ Nursery school } & yes & 491 & 42.7 & 380 & 38.3 & 0.041 \\
\hline & & no & 660 & 57.3 & 612 & 61.7 & \\
\hline & \multirow[t]{2}{*}{ Kinder- garten } & yes & 415 & 36.1 & 402 & 40.5 & 0.034 \\
\hline & & no & 736 & 63.9 & 590 & 59.5 & \\
\hline & \multirow{2}{*}{$\begin{array}{l}\text { Centers for early childhood } \\
\text { education and care }\end{array}$} & yes & 77 & 6.7 & 64 & 6.5 & 0.825 \\
\hline & & no & 1074 & 93.3 & 928 & 93.6 & \\
\hline & \multirow[t]{2}{*}{ Grandparents and relatives } & yes & 49 & 4.3 & 58 & 5.9 & 0.092 \\
\hline & & no & 1102 & 95.7 & 934 & 94.2 & \\
\hline
\end{tabular}

Page 10/19 


\begin{tabular}{|c|c|c|c|c|c|c|c|}
\hline & \multirow[t]{2}{*}{ None of the above } & yes & 142 & 12.3 & 123 & 12.4 & 0.965 \\
\hline & & no & 1109 & 87.7 & 869 & 87.6 & \\
\hline \multirow[t]{5}{*}{ Life style } & \multirow[t]{5}{*}{ Eating breakfast } & everyday & 1103 & 95.8 & 910 & 91.73 & 0.0002 \\
\hline & & 4-5 days per week & 39 & 3.4 & 68 & 6.9 & \\
\hline & & 2-3 days per week & 4 & 0.4 & 1 & 0.1 & \\
\hline & & 1 day or less per week & 5 & 0.4 & 13 & 1.3 & \\
\hline & & I do not eat at all & 0 & 0.0 & 0 & 0.0 & \\
\hline \multicolumn{8}{|l|}{$\mathrm{p}: \chi^{2}$ test } \\
\hline t: $t$ test & & & & & & & \\
\hline
\end{tabular}

Table2 Child' health and lifestyle situation by food diversity group

\begin{tabular}{|c|c|c|c|c|c|c|c|}
\hline & & & \multicolumn{5}{|c|}{ Food diversity score group } \\
\hline & & & \multicolumn{2}{|c|}{ Higher ( $\geq 4$ points) } & \multicolumn{3}{|c|}{ Lower ( $\leq 3$ points) } \\
\hline & & & \multicolumn{2}{|c|}{$(n=1151,53.7 \%)$} & \multicolumn{2}{|c|}{$(n=992,46.3 \%)$} & \multirow[b]{2}{*}{$\mathrm{p}$} \\
\hline & & & mean & SD & mean & SD & \\
\hline \multirow[t]{2}{*}{ Age $\dagger$} & \multicolumn{2}{|l|}{ years old } & 4.2 & 1.1 & 4.3 & 1.1 & 0.208 \\
\hline & & & $\mathrm{n}$ & $\%$ & $\mathrm{n}$ & $\%$ & प \\
\hline \multirow[t]{2}{*}{ Sex } & male & & 582 & 50.6 & 522 & 52.6 & 0.342 \\
\hline & female & & 569 & 49.4 & 470 & 47.4 & \\
\hline \multirow[t]{8}{*}{ Nutritional status } & Height & $(\mathrm{cm})$ & 100.8 & 8.6 & 100.9 & 8.3 & 0.836 \\
\hline & Weight & $(\mathrm{kg})$ & 15.8 & 2.9 & 15.9 & 2.8 & 0.550 \\
\hline & \multicolumn{2}{|c|}{$+30 \rrbracket \leq$ (obesity) } & 4 & 0.4 & 10 & 1.0 & 0.151 \\
\hline & \multicolumn{2}{|c|}{ +30 to 20区 (overweight) } & 14 & 1.2 & 12 & 1.2 & \\
\hline & \multicolumn{2}{|c|}{+15 to 20 ( (overweight tendency) } & 36 & 3.1 & 21 & 2.1 & \\
\hline & \multicolumn{2}{|c|}{-15 to $₫ 15 \rrbracket$ (standard) } & 1060 & 92.1 & 928 & 93.6 & \\
\hline & \multicolumn{2}{|c|}{-15 to -208 (underweight tendency) } & 25 & 2.2 & 14 & 1.4 & \\
\hline & \multicolumn{2}{|c|}{$\leq-208$ (underweight) } & 12 & 1.0 & 7 & 0.7 & \\
\hline \multirow[t]{2}{*}{ Food allergy symptoms } & & yes & 184 & 16.0 & 162 & 16.3 & 0.829 \\
\hline & & no & 967 & 84.0 & 880 & 83.7 & \\
\hline \multirow[t]{2}{*}{ Tooth decay } & & yes & 194 & 16.9 & 214 & 21.6 & 0.006 \\
\hline & & no & 955 & 83.1 & 777 & 78.4 & \\
\hline \multicolumn{8}{|c|}{ Time spent on TV, video or games } \\
\hline & \multirow[t]{3}{*}{ weekday } & None & 16 & 1.4 & 13 & 1.3 & 0.005 \\
\hline & & $<2$ hours / day & 908 & 78.9 & 725 & 73.1 & \\
\hline & & $\geq 2$ hours / day & 227 & 19.7 & 254 & 25.6 & \\
\hline & \multirow[t]{3}{*}{ weekend } & None & 10 & 0.9 & 9 & 0.9 & 0.002 \\
\hline & & $<2$ hours / day & 704 & 61.2 & 533 & 53.7 & \\
\hline & & $\geq 2$ hours / day & 437 & 38.0 & 450 & 45.4 & \\
\hline \multicolumn{8}{|l|}{$\mathrm{p}: \chi^{2}$ test } \\
\hline \multicolumn{8}{|l|}{ t: t test } \\
\hline
\end{tabular}


Table $₫$ Food intakes by food diversity group

Page 12/19 


\begin{tabular}{|c|c|c|c|c|c|c|}
\hline & & \multicolumn{5}{|c|}{ Food diversity score group } \\
\hline & & \multicolumn{2}{|c|}{ Higher ( $\geq 4$ points) } & \multicolumn{3}{|c|}{ Lower ( $\leq 3$ points) } \\
\hline \multirow[t]{2}{*}{ food category } & & \multicolumn{2}{|c|}{$(n=1151,53.7 \%)$} & \multicolumn{3}{|c|}{$(n=992,46.3 \%)$} \\
\hline & frequency & $\mathrm{n}$ & $\%$ & $\mathrm{n}$ & $\%$ & ? \\
\hline grain & $\geq 2$ times per day & 1137 & 98.78 & 958 & 96.57 & 0.002 \\
\hline \multirow[t]{5}{*}{ group } & Once a day & 12 & 1.04 & 21 & 2.12 & \\
\hline & 4-6 days / week & 1 & 0.09 & 11 & 1.11 & \\
\hline & 1-3 days / week & 0 & 0 & 2 & 0.2 & \\
\hline & less than once a week & 1 & 0.09 & 0 & 0.0 & \\
\hline & have not eaten yet & 0 & 0 & 0 & 0.0 & \\
\hline \multirow[t]{6}{*}{ fish } & $\geq 2$ times per day & 116 & 10.08 & 4 & 0.4 & $<.0001$ \\
\hline & Once a day & 244 & 21.2 & 10 & 1.01 & \\
\hline & 4-6 days / week & 290 & 25.2 & 213 & 21.47 & \\
\hline & 1-3 days / week & 460 & 39.97 & 682 & 68.75 & \\
\hline & less than once a week & 40 & 3.48 & 81 & 8.17 & \\
\hline & have not eaten yet & 1 & 0.09 & 2 & 0.2 & \\
\hline \multirow[t]{6}{*}{ meat } & $\geq 2$ times per day & 264 & 22.9 & 16 & 1.6 & $<.0001$ \\
\hline & Once a day & 386 & 33.5 & 48 & 4.8 & \\
\hline & 4-6 days / week & 365 & 31.7 & 583 & 58.8 & \\
\hline & 1-3 days / week & 132 & 11.5 & 325 & 32.8 & \\
\hline & less than once a week & 3 & 0.3 & 18 & 1.8 & \\
\hline & have not eaten yet & 1 & 0.1 & 2 & 0.2 & \\
\hline \multirow[t]{6}{*}{ eggs } & $\geq 2$ times per day & 85 & 7.38 & 4 & 0.4 & $<.0001$ \\
\hline & Once a day & 430 & 37.36 & 48 & 4.84 & \\
\hline & 4-6 days / week & 336 & 29.19 & 425 & 42.84 & \\
\hline & 1-3 days / week & 230 & 19.98 & 407 & 41.03 & \\
\hline & less than once a week & 54 & 4.69 & 93 & 9.38 & \\
\hline & have not eaten yet & 16 & 1.39 & 15 & 1.51 & \\
\hline \multirow[t]{6}{*}{ soybeans and soy products } & $\geq 2$ times per day & 150 & 13.0 & 6 & 0.6 & $<.0001$ \\
\hline & Once a day & 417 & 36.23 & 31 & 3.13 & \\
\hline & 4-6 days / week & 307 & 26.67 & 363 & 36.59 & \\
\hline & 1-3 days /week & 240 & 20.85 & 488 & 49.19 & \\
\hline & less than once a week & 36 & 3.13 & 100 & 10.08 & \\
\hline & have not eaten yet & 1 & 0.09 & 4 & 0.4 & \\
\hline \multirow[t]{6}{*}{ vegetables } & $\geq 2$ times per day & 836 & 72.63 & 331 & 33.37 & $<.0001$ \\
\hline & Once a day & 273 & 23.72 & 241 & 24.29 & \\
\hline & 4-6 days /week & 28 & 2.43 & 271 & 27.32 & \\
\hline & 1-3 days / week & 13 & 1.13 & 125 & 12.6 & \\
\hline & less than once a week & 1 & 0.09 & 21 & 2.12 & \\
\hline & have not eaten yet & 0 & 0 & 3 & 0.3 & \\
\hline fruit & $\geq 2$ times per day & 221 & 19.2 & 12 & 1.2 & $<.0001$ \\
\hline
\end{tabular}




\begin{tabular}{|c|c|c|c|c|c|c|}
\hline & Once a day & 521 & 45.3 & 66 & 6.7 & \\
\hline & 4-6 days / week & 216 & 18.8 & 379 & 38.2 & \\
\hline & 1-3 days / week & 154 & 13.4 & 398 & 40.1 & \\
\hline & less than once a week & 38 & 3.3 & 132 & 13.3 & \\
\hline & have not eaten yet & 1 & 0.1 & 5 & 0.5 & \\
\hline \multirow[t]{6}{*}{ milk } & $\geq 2$ times per day & 533 & 46.3 & 237 & 23.9 & $<.0001$ \\
\hline & Once a day & 499 & 43.4 & 285 & 28.7 & \\
\hline & 4-6 days / week & 52 & 4.5 & 263 & 26.5 & \\
\hline & 1-3 days /week & 45 & 3.9 & 164 & 16.5 & \\
\hline & less than once a week & 10 & 0.9 & 36 & 3.6 & \\
\hline & have not eaten yet & 12 & 1.0 & 7 & 0.7 & \\
\hline \multirow[t]{2}{*}{ sweetened beverage } & $\geq 2$ times per day & 125 & 10.86 & 95 & 9.58 & 0.491 \\
\hline & Once a day & 239 & 20.8 & 198 & 19.96 & \\
\hline \multirow{4}{*}{ food } & 4-6 days /week & 165 & 14.3 & 160 & 16.13 & \\
\hline & 1-3 days / week & 370 & 32.2 & 339 & 34.17 & \\
\hline & less than once a week & 224 & 19.5 & 183 & 18.45 & \\
\hline & have not eaten yet & 28 & 2.4 & 17 & 1.71 & \\
\hline \multirow[t]{6}{*}{ Confec-tionery } & $\geq 2$ times per day & 149 & 12.95 & 108 & 10.89 & 0.212 \\
\hline & Once a day & 555 & 48.22 & 483 & 48.69 & \\
\hline & 4-6 days / week & 198 & 17.2 & 189 & 19.05 & \\
\hline & 1-3 days / week & 177 & 15.38 & 167 & 16.83 & \\
\hline & less than once a week & 64 & 5.56 & 42 & 4.23 & \\
\hline & have not eaten yet & 8 & 0.7 & 3 & 0.3 & \\
\hline \multirow[t]{6}{*}{ instant noodle } & $\geq 2$ times per day & 0 & 0 & 0 & 0 & $<.0001$ \\
\hline & Once a day & 2 & 0.17 & 3 & 0.3 & \\
\hline & 4-6 days / week & 9 & 0.78 & 5 & 0.5 & \\
\hline & 1-3 days / week & 77 & 6.69 & 121 & 12.2 & \\
\hline & less than once a week & 804 & 69.85 & 738 & 74.4 & \\
\hline & have not eaten yet & 259 & 22.5 & 125 & 12.6 & \\
\hline \multirow[t]{7}{*}{ fast food } & $\geq 2$ times per day & 0 & 0.0 & 0 & 0.0 & 0.004 \\
\hline & Once a day & 4 & 0.4 & 1 & 0.1 & \\
\hline & 4-6 days /week & 11 & 1.0 & 7 & 0.7 & \\
\hline & 1-3 days / week & 110 & 9.6 & 126 & 12.7 & \\
\hline & less than once a week & 941 & 81.8 & 816 & 82.3 & \\
\hline & have not eaten yet & 85 & 7.4 & 42 & 4.2 & \\
\hline & & Ismean & SE & Ismean & SE & \\
\hline Food diversity score $†$ & 8 points/day & 5.3 & 1.3 & 2.3 & 0.8 & 0.0002 \\
\hline Processed food score + & 4 points/day & 0.9 & 0.8 & 0.9 & 0.8 & $<.0001$ \\
\hline \multicolumn{7}{|l|}{$\mathrm{p}: \chi^{2}$ test } \\
\hline \multicolumn{7}{|l|}{ †: ANCOVA } \\
\hline \multicolumn{7}{|c|}{$\begin{array}{l}\text { †: adjusted relationship for the child, sex of child, employment status of mother, family living together, subjective economic status and leisure } \\
\text { time, caregiver of the child during the day }\end{array}$} \\
\hline
\end{tabular}


Food diversity score: the total number of 8 food groups (grain, fish, meat, eggs, soybeans and soy products, vegetables, fruit and milk) eating at least once a day

Processed food score: the total number of 4 food items (sweetened beverage, confectionery, instant noodle and fast food) eating at least once a day

Table 4 Parent's care on diet of child by food diversity group

\begin{tabular}{|c|c|c|c|c|c|c|c|}
\hline & & & \multicolumn{5}{|c|}{ Food diversity score group } \\
\hline & & & \multicolumn{2}{|c|}{ Higher ( $\geq 4$ points) } & \multicolumn{3}{|c|}{ Lower ( $\leq 3$ points) } \\
\hline & & & \multicolumn{2}{|c|}{$(n=1151,53.7 \%)$} & \multicolumn{2}{|c|}{$(n=992,46.3 \%)$} & \\
\hline \multicolumn{3}{|c|}{ Parent's care on diet of child ( 13 items) } & $\mathrm{n}$ & $\%$ & $\mathrm{n}$ & $\%$ & ] \\
\hline \multirow[t]{10}{*}{ Food } & Nutritional balance & yes & 923 & 80.2 & 662 & 66.7 & $<.0001$ \\
\hline & & no & 228 & 19.8 & 330 & 33.3 & \\
\hline & Flavoring and seasoning & yes & 477 & 41.4 & 351 & 35.4 & 0.004 \\
\hline & & no & 674 & 58.6 & 641 & 64.6 & \\
\hline & Size or softness & yes & 248 & 21.6 & 191 & 19.3 & 0.190 \\
\hline & & no & 903 & 78.5 & 801 & 80.8 & \\
\hline & Assorted arrange and colors & yes & 253 & 22.0 & 164 & 16.5 & 0.002 \\
\hline & & no & 898 & 78.0 & 828 & 83.5 & \\
\hline & Amount & yes & 569 & 49.4 & 452 & 45.6 & 0.074 \\
\hline & & no & 582 & 50.6 & 540 & 54.4 & \\
\hline \multirow[t]{4}{*}{ Snack } & Contents & yes & 189 & 16.4 & 98 & 9.9 & $<.0001$ \\
\hline & & no & 962 & 83.6 & 894 & 90.1 & \\
\hline & Amount & yes & 464 & 40.3 & 349 & 35.2 & 0.015 \\
\hline & & no & 687 & 59.7 & 643 & 64.8 & \\
\hline \multirow[t]{6}{*}{ Mealtime practice } & Regular mealtimes & yes & 576 & 50.0 & 399 & 40.2 & $<.0001$ \\
\hline & & no & 575 & 50.0 & 593 & 59.8 & \\
\hline & Chewing well & yes & 356 & 30.9 & 246 & 24.8 & 0.002 \\
\hline & & no & 795 & 69.1 & 746 & 75.2 & \\
\hline & Table manners & yes & 794 & 69.0 & 660 & 66.5 & 0.226 \\
\hline & & no & 357 & 31.0 & 332 & 33.5 & \\
\hline \multirow[t]{7}{*}{ Parent-child communication } & Enjoyment of eating & yes & 592 & 51.4 & 464 & 46.8 & 0.032 \\
\hline & & no & 559 & 48.6 & 528 & 58.2 & \\
\hline & Eating together & yes & 826 & 71.8 & 669 & 67.4 & 0.030 \\
\hline & & no & 325 & 28.2 & 323 & 32.6 & \\
\hline & Cooking together & yes & 134 & 11.6 & 96 & 9.7 & 0.143 \\
\hline & & no & 1017 & 88.4 & 896 & 90.3 & \\
\hline & & & mean & SD & mean & SD & $\mathrm{p}$ \\
\hline \multicolumn{3}{|c|}{ Total number of the parent's care on diet of child $\otimes 13$ points $\nabla \dagger$} & 5.6 & 2.7 & 4.8 & 2.6 & $<.0001$ \\
\hline \multicolumn{8}{|l|}{$\mathrm{p}: \chi^{2}$ test } \\
\hline \multicolumn{8}{|l|}{ t: t test } \\
\hline
\end{tabular}


Table 5 Factors related food diversity score

\begin{tabular}{|c|c|c|}
\hline Factors & Standardized parameter estimate & $\mathrm{p}$ \\
\hline Total number of the parental care on diet of child & 0.16 & $<.0001$ \\
\hline Age of mother & 0.06 & 0.01 \\
\hline Age of child & -0.04 & 0.08 \\
\hline Subjective economic status & -0.06 & 0.003 \\
\hline Time spent on TV, video or games (weekday) & -0.06 & 0.01 \\
\hline Skipping breakfast of mother & - & \\
\hline Food allergy symptoms & - & \\
\hline Tooth decay & - & \\
\hline \multicolumn{3}{|l|}{ SE: standard error } \\
\hline \multicolumn{3}{|l|}{ P: selected by stepwise method } \\
\hline \multicolumn{3}{|c|}{$\begin{array}{l}\text { Factors related to FDS: total number of the parent's care on diet of children, subjective economic status, food allergies, tooth decay, time spent } \\
\text { on TV, video or game, child's age and mother's age }\end{array}$} \\
\hline \multicolumn{3}{|c|}{ Continuous variable: total number of the parent's care on diet of children, child's age and mother's age } \\
\hline \multicolumn{3}{|c|}{$\begin{array}{l}\text { Nominal variable (Ordinal scale): subjective economic status (1: affluent, somewhat, } 2 \text { : neither, } 3 \text { : not so much, no afford not at all, do not wan } \\
\text { answer), food allergies symptoms ( } 1: y e s, 2: \text { no), tooth decay, (1:yes, } 2: \text { no) and time spent on TV, video or game (1:None, } 2:<2 \text { hours } / \text { day, } 3: \geq 2 \\
\text { hours /day) }\end{array}$} \\
\hline
\end{tabular}

Table 6 Relationship between food diversity and parent's care on diet of child 


\begin{tabular}{|c|c|c|c|c|c|c|c|c|c|c|c|c|c|c|}
\hline \multirow{2}{*}{\multicolumn{2}{|c|}{$\begin{array}{l}\text { Parent's care on diet of child } \\
\text { (13 items) }\end{array}$}} & \multicolumn{4}{|c|}{ Model 1} & \multirow{3}{*}{$\begin{array}{l}\mathrm{p} \\
<.0001\end{array}$} & \multicolumn{3}{|c|}{ Model 2} & \multirow[b]{2}{*}{$p$} & \multicolumn{3}{|c|}{ Stepwise } & \multirow[b]{2}{*}{$p$} \\
\hline & & & OR & $95 \% \mathrm{C}$ & & & OR & $95 \% \mathrm{Cl}$ & & & OR & $95 \% \mathrm{C}$ & & \\
\hline \multirow[t]{10}{*}{ Food } & $\begin{array}{l}\text { Nutritional } \\
\text { balance }\end{array}$ & yes & 1.91 & 1.56 & 2.35 & & 1.91 & 1.56 & 2.35 & $<.0001$ & 1.76 & 1.44 & 2.16 & $<.0001$ \\
\hline & & no & 1.00 & & & & 1.00 & & & & 1.00 & & & \\
\hline & $\begin{array}{l}\text { Flavoring } \\
\text { and } \\
\text { seasoning }\end{array}$ & yes & 1.24 & 1.03 & 1.48 & 0.022 & 1.24 & 1.03 & 1.48 & 0.020 & & & & \\
\hline & & no & 1.00 & & & & 1.00 & & & & & & & \\
\hline & $\begin{array}{l}\text { Size or } \\
\text { softness }\end{array}$ & yes & 1.17 & 0.94 & 1.45 & 0.160 & 1.17 & 0.94 & 1.45 & 0.163 & & & & \\
\hline & & no & 1.00 & & & & 1.00 & & & & & & & \\
\hline & Assorted & yes & 1.35 & 1.08 & 1.69 & 0.009 & 1.34 & 1.07 & 1.68 & 0.011 & & & & \\
\hline & and color & no & 1.00 & & & & 1.00 & & & & & & & \\
\hline & Amount & yes & 1.18 & 0.99 & 1.41 & 0.061 & 1.19 & 1.00 & 1.41 & 0.057 & & & & \\
\hline & & no & 1.00 & & & & 1.00 & & & & & & & \\
\hline \multirow[t]{4}{*}{ Snack } & Contents & yes & 1.72 & 1.32 & 2.25 & $<.0001$ & 1.72 & 1.31 & 2.24 & $<.0001$ & 1.41 & 1.07 & 1.86 & 0.014 \\
\hline & & no & 1.00 & & & & 1.00 & & & & 1.00 & & & \\
\hline & Amount & yes & 1.23 & 1.03 & 1.48 & 0.026 & 1.23 & 1.03 & 1.48 & 0.027 & & & & \\
\hline & & no & 1.00 & & & & 1.00 & & & & & & & \\
\hline \multirow[t]{6}{*}{$\begin{array}{l}\text { Mealtime } \\
\text { practice }\end{array}$} & $\begin{array}{l}\text { Regular } \\
\text { mealtimes }\end{array}$ & yes & 1.45 & 1.21 & 1.73 & $<.0001$ & 1.44 & 1.21 & 1.72 & $<.0001$ & 1.30 & 1.08 & 1.55 & 0.005 \\
\hline & & no & 1.00 & & & & 1.00 & & & & 1.00 & & & \\
\hline & $\begin{array}{l}\text { Chewing } \\
\text { well }\end{array}$ & yes & 1.34 & 1.10 & 1.63 & 0.003 & 1.34 & 1.10 & 1.63 & 0.004 & 1.20 & 0.98 & 1.46 & 0.076 \\
\hline & & no & 1.00 & & & & 1.00 & & & & 1.00 & & & \\
\hline & $\begin{array}{l}\text { Dietary } \\
\text { manners }\end{array}$ & yes & 1.11 & 0.92 & 1.34 & 0.273 & 1.11 & 0.92 & 1.34 & 0.282 & & & & \\
\hline & & no & 1.00 & & & & 1.00 & & & & & & & \\
\hline \multirow[t]{6}{*}{$\begin{array}{l}\text { Parent-child } \\
\text { communication }\end{array}$} & $\begin{array}{l}\text { Enjoyment } \\
\text { of eating }\end{array}$ & yes & 1.16 & 0.97 & 1.38 & 0.097 & 1.16 & 0.97 & 1.38 & 0.100 & & & & \\
\hline & & no & 1.00 & & & & 1.00 & & & & & & & \\
\hline & $\begin{array}{l}\text { Eating } \\
\text { together }\end{array}$ & yes & 1.23 & 1.02 & 1.48 & 0.034 & 1.22 & 1.01 & 1.48 & 0.037 & & & & \\
\hline & & no & 1.00 & & & & 1.00 & & & & & & & \\
\hline & $\begin{array}{l}\text { Cooking } \\
\text { together }\end{array}$ & yes & 1.20 & 0.90 & 1.60 & 0.216 & 1.19 & 0.89 & 1.58 & 0.246 & & & & \\
\hline & & no & 1.00 & & & & 1.00 & & & & & & & \\
\hline \multicolumn{15}{|c|}{ Food diversity score (0: $\leq$ \points ; $1: \geq \rrbracket$ points) } \\
\hline \multicolumn{15}{|c|}{$\begin{array}{l}\text { Model 1: adjusted for the relationship with the child (mother or father), child's sex, employment status of parent (yes or no), and family members } \\
\text { in the household (other children, grandparents, and others) }\end{array}$} \\
\hline \multicolumn{15}{|c|}{$\begin{array}{l}\text { Model 2: adjusted for the relationship with the child (mother or father), child's sex, employment status of parent (yes or no), family living together } \\
\text { (other children, grandparents, and others), subjective economic status (affluent, somewhat, neither, not so much, or not able to afford at all), } \\
\text { leisure time (affluent, somewhat, neither, not so much, not at all), and place where the child spends time during the day (nursery school, } \\
\text { kindergarten, center for early childhood education and care, with grandparents, with relatives, staying at home) }\end{array}$} \\
\hline
\end{tabular}


Figures
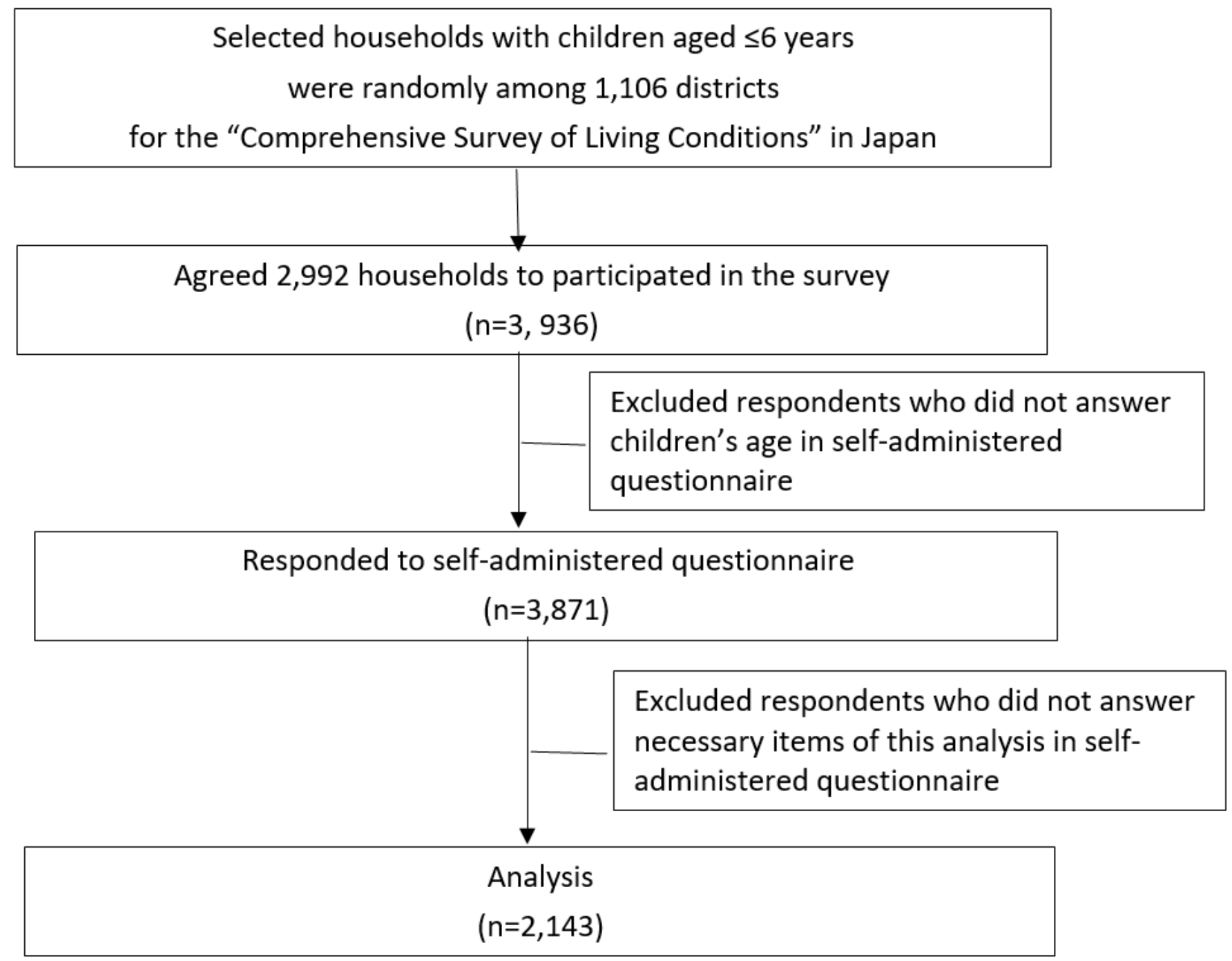

Figure 1

Study population and procedure diagram of this study 


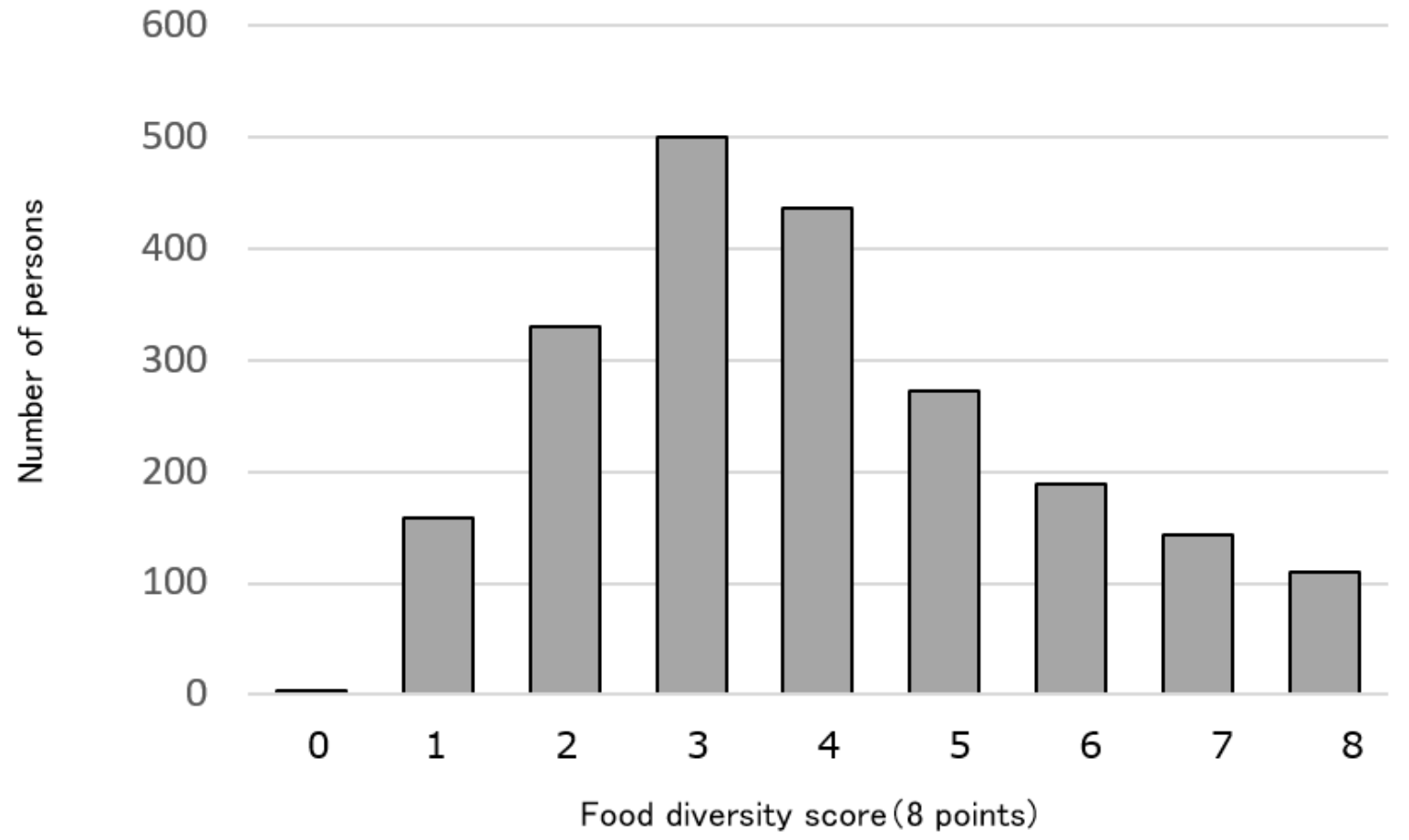

Figure 2

Distribution of Food diversity score in children

Supplementary Files

This is a list of supplementary files associated with this preprint. Click to download.

- STROBEchecklistcrosssectional1.doc 